\title{
Cardiology
}

\section{Electrical and Contractile Properties of the Heart Ventricle in Response to Ambient Temperature Changes in Frog Rana temporaria}

\author{
Natalya A. Kibler, PhD*; Vladimir P. Nuzhny, PhD; Valentina I. Prosheva, PhD \\ Institute of Physiology, Komi Science Center, Ural Branch of the RAS \\ Syktyvkar, Komi Republic, the Russian Federation
}

\begin{abstract}
The aim of the study was to investigate the dynamics of change in the intraventricular pressure, depolarization and repolarization processes on the ventricular epicardium (VE) in Rana temporaria in response to a rise in ambient temperature. By methods of catheterization and electrophysiological mapping the dynamics of the intraventricular pressure change, the processes of depolarization and repolarization on the epicardium of the heart ventricle in adult frogs in a temperature range from $10^{\circ} \mathrm{C}$ to $20^{\circ} \mathrm{C}$ were studied. We found that the rise in body temperature by $10^{\circ} \mathrm{C}$ led to increase of the maximal systolic ventricular pressure (MSVP), maximal value of the MSVP derivative and maximal rate of MSVP decline but to a decrease in dispersion of depolarization time and durations of activation-recovery intervals on the ventral and dorsal sides of VE. The role of the electrical inhomogeneity of the myocardium was shown to be a modulator performing fine adjustment to factors in the external environment of the organism. (International Journal of Biomedicine. 2017;7(3):180-184.)
\end{abstract}

Key Words: intraventricular pressure $\bullet$ ventricular epicardium $\bullet$ depolarization $\bullet$ repolarization $\bullet$ temperature $\bullet$ Rana temporaria

\section{Abbreviations}

AT, activation time; ARIs, activation-recovery intervals; ECG, electrocardiogram; EDP, end-diastolic pressure; HR, heart rate; MSVP, maximal systolic ventricular pressure; VE, ventricular epicardium.

\section{Introduction}

The ambient temperature can limit or increase absorption of $\mathrm{O}_{2}$ in animals; thus it has a drastic effect on the cardiovascular system. $^{(1-4)}$ Ectothermic animals inhabiting regions with a temperate climate have to compensate for temperature changes in order to cope with the seasonal thermal variations. It is known that ectothermic vertebrate hearts are highly sensitive to temperature effects. Therefore, ectothermic animals can be used to understand mechanisms controlling the electrical and contractile functions of the myocardium in response to changes in environmental temperature. ${ }^{(5-7)}$

At present there are only a few studies of the electrophysiological processes that occur in a frog's heart ventricle under changes in ambient temperature. ${ }^{(8,9)}$ It has been shown that when the body temperature in the frogs is

*Corresponding author: Natalya A. Kibler, PhD. Laboratory of Cardiac Physiology, Institute of Physiology, Komi Science Center, Ural Branch of the RAS, Syktyvkar, Komi Republic, Russia. E-mail: natanadya@mail.ru decreased to $10^{\circ} \mathrm{C}$, then $\mathrm{HR}$ is diminished and the durations of QRS and ST-T complexes of ECG are lengthened. At the same time, the repolarization sequence is changed on the ventricular epicardium (VE). There are no data about cardiohemodynamic in amphibia under temperature effects.

The aim of the study was to investigate the dynamics of change in the intraventricular pressure, depolarization and repolarization processes on the VE in Rana temporaria in response to a rise in ambient temperature.

\section{Materials and methods}

\section{Animals and surgical procedure}

The investigation conforms with the Guide for the Care and Use of Laboratory Animals published by the US National Institutes of Health (NIH Publication No. 85-23, revised 1996). The Animal Care and Use Committee of Institute of Physiology of the Komi Science Center of the Russian Academy of Sciences approved the experimental protocol (approved number: 29). 
Data were obtained from 18 adult frogs Rana temporaria of both sexes (age, 2-3 years old). Two groups of animals were investigated: Group I consisted of 8 frogs with body temperature $10^{\circ} \mathrm{C}$ (body mass, $32 \pm 7 \mathrm{~g}$ ), and Group II consisted of 10 frogs with body temperature $20^{\circ} \mathrm{C}$ (body mass, $40 \pm 5 \mathrm{~g}$ ). The body temperature was measured rectally by means of a temperature sensor of the hemodynamic apparatus Prucka MacLab 2000 system. Measurements of rectal temperature did not show an essential difference between a frog's body temperature and the chamber of habitat. This is in agreement with the findings of other authors. ${ }^{(5,10)}$ As in our previous studies on amphibians, ${ }^{(11,12)}$ the animals were anaesthetized by placing them for 3 minutes in a jar containing $40 \%$ ethanol. After that, the ventral thoracic wall was removed and the pericardium was cut open. During the experiment, the heart was flushed with Ringer's solution. At the end of the experiment, the animals were euthanized by the intravenous injection of an overdose of alcoholic solution.

Hemodynamic recording

The hemodynamic variables were determined with the Prucka MacLab 2000 system (GE Medical System, GmbH). The pressure in the ventricle was measured with a catheter (internal diameter, $1 \mathrm{~mm}$ ) filled with the heparinized $0.9 \%$ saline inserted via the free wall into the ventricular cavity. Invasive monitoring of the pressure was carried out using transducers, transforming blood pressure inside of the vessels as the transducer registered mechanical changes. IP and ECG in standard bipolar limb leads were recorded synchronously. Hemodynamic parameters measured included MSVP $(\mathrm{mmHg})$, EDP $(\mathrm{mmHg})$, maximal value of the MSVP derivative $(+\mathrm{dP} /$ $\left.\mathrm{dt}_{\max }, \mathrm{mmHg} / \mathrm{s}\right)$, maximal rate of MSVP decline $\left(-\mathrm{dP}_{\mathrm{din}}\right.$, $\mathrm{mmHg} / \mathrm{s}$ ). The durations of QRS complex and QT interval were measured also.

\section{Electrocardiographic recording and analysis}

Unipolar electrograms and ECGs were recorded in reference to Wilson's central terminal. Simultaneous data acquisition was done by means of a custom-designed mapping system (16 bits; bandwidth 0.05 to $1000 \mathrm{~Hz}$; sampling rate 4000 $\mathrm{Hz}$ ). Standard bipolar limb lead ECGs were recorded with an application of subcutaneous steel needle electrodes. Registration of an epicardial electrogram was performed by using a matrix ( 5 $\mathrm{mm} \times 5 \mathrm{~mm}$ ) containing 64 electrodes at the sinoatrial rhythm. The matrix was alternately superimposed on the central portion of the ventral and dorsal sides of VE in such a way that the superior border of the matrix grasped the basal part and the inferior border - part of the ventricular apex (Fig.1).

In every epicardial lead, the activation time (AT), the repolarization time (RT) and the activation-recovery intervals (ARIs) were obtained. The latter was used to assess local repolarization durations. AT, RT and ARIs were determined as $\mathrm{dV} / \mathrm{dt}_{\text {min }}$ during QRS complex, $\mathrm{dV} / \mathrm{dt}_{\text {max }}$ during ST-T, and the difference between RT and AT, respectively. The values were determined automatically, inspected by the observer and corrected manually if necessary. In each set of simultaneously recorded electrograms, the beginning of the QRS complex in the II limb lead was chosen as a reference time point with respect to which ATs and RTs were measured in a given set of electrograms.
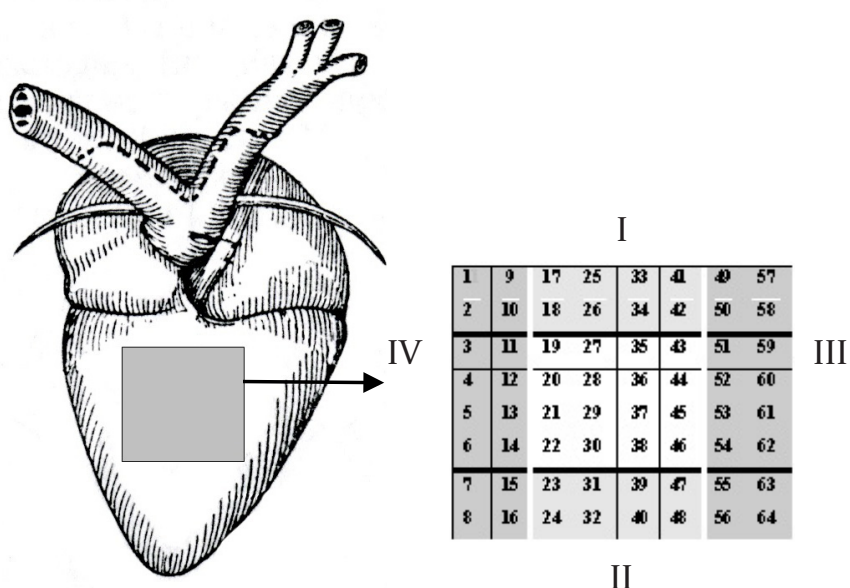

Fig. 1. Scheme of the position of the matrix $(5 \mathrm{~mm} \times 5 \mathrm{~mm})$ with electrodes on the epicardial surface of the ventral side of the frog ventricle. Numbers from 1 to 64 show the location of the electrodes on the matrix. Black-and-white marking on the matrix shows the boundaries of the epicardial mapping zones.

$I$ - the basal region of the matrix; II - the apical region of the matrix $I I I$ - the right portion of the matrix; IV - the left portion of the matrix.

The dispersion of ATs, ARIs, and RTs of the ventricle were taken as the difference between the maximal and minimal AT, RT and ARIs values in a set of recorded electrograms, respectively.

In order to construct isochronal activation maps, the zero point was assigned to the timing of the epicardial activation breakthrough. Similarly, the zero points in the repolarization maps identify for the earliest repolarization on the epicardium.

Statistical examination was done using statistical package Primer of Biostatics 4.03 and SPSS 11.5 using Wilcoxon test for paired comparisons and the Fridman test followed by the Wilcoxon test. Data are presented as mean \pm SD. A probability value of $P<0.05$ was considered statistically significant.

\section{Results}

At the body temperature of $10^{\circ} \mathrm{C}, \mathrm{HR}$ in frogs was $24.3 \pm 2.3 \mathrm{bpm}$, and the duration of QRS complex and QT interval was $83.4 \pm 4.5 \mathrm{~ms}$ and $1375.6 \pm 363.2 \mathrm{~ms}$, respectively. When body temperature was increased to $20^{\circ} \mathrm{C}$, HR was raised to $38.8 \pm 3.1 \mathrm{bpm}(P<0.05)$, but the duration of QRS and QT interval was decreased to $68.7 \pm 7.2 \mathrm{~ms}$ and $783.3 \pm 102.2 \mathrm{~ms}$, respectively.

At $10^{\circ} \mathrm{C}$, the earliest foci of depolarization were located in the basal part of the epicardial fragment on the dorsal surface $(P<0.05)$, and the latest foci in the left part of the epicardial fragment on the ventral surface. The sequence of activation on the dorsal surface of the epicardium is from the base to the apex $(P<0.05)$ (Table 1). For frogs in Group I, dispersion of AT in both epicardial surfaces was more than for those in Group II $(P<0.05)$ (Fig. 2). The duration of repolarization on the ventral surface of the epicardium was greater than on the dorsal one $(P<0.05)$ (Fig. 2). Dispersion of ARIs time in both epicardial surfaces of the ventricle was $559.0 \pm 200.8 \mathrm{~ms}$ in total (Fig. 2). At the same time, dispersion of ARIs time was less on the dorsal surface of the ventricle than on the ventral one $(P<0.05)$ (Fig. 2). 
Table 1.

Chronotopographyc performance of different zones of $V E$ of the frog heart at the body temperature of $10^{\circ} \mathrm{C}$ (Group I) and $20^{\circ} \mathrm{C}$ (Group II)

\begin{tabular}{|l|c|c|c|c|c|}
\hline \multicolumn{2}{|c|}{$\begin{array}{c}\text { Epicardial } \\
\text { areas of } \\
\text { the ventricle }\end{array}$} & \multicolumn{2}{|c|}{ Depolarization time } & \multicolumn{2}{c|}{ Repolarization time } \\
\cline { 2 - 6 } & I & $35.4 \pm 12.3$ & $21.8 \pm 11.8 \#$ & $961.5 \pm 342.2$ & $855.4 \pm 250.7$ \\
\cline { 2 - 6 } VS & II & $35.8 \pm 10.6$ & $32.5 \pm 12.3$ & $950.4 \pm 342.5$ & $858.8 \pm 249.5$ \\
\cline { 2 - 6 } & III & $32.7 \pm 10.2^{*}$ & $22.5 \pm 13.4^{*}$ & $972.2 \pm 334.6$ & $828.1 \pm 245.6^{*}$ \\
\cline { 2 - 6 } & IV & $40.2 \pm 10.7$ & $38.1 \pm 13.1$ & $963.5 \pm 346.2$ & $918.2 \pm 252.1$ \\
\hline \multirow{4}{*}{ DS } & I & $26.6 \pm 9.4 \dagger$ & $30.4 \pm 9.4 \dagger$ & $1243.6 \pm 469.8^{\wedge}$ & $813.5 \pm 220.1$ \\
\cline { 2 - 6 } & II & $35.4 \pm 10.8$ & $43.2 \pm 10.6$ & $1250.0 \pm 450.4^{\wedge}$ & $804.7 \pm 235.7$ \\
\cline { 2 - 6 } & III & $29.6 \pm 12.7$ & $44.1 \pm 14.3$ & $1236.2 \pm 478.5^{\wedge}$ & $814.4 \pm 221.1$ \\
\cline { 2 - 6 } & IV & $31.4 \pm 14.7$ & $37.2 \pm 17.5$ & $1245.7 \pm 418.4^{\wedge}$ & $805.7 \pm 240.7$ \\
\hline
\end{tabular}

$* P<0.05$ - in relation to the left part of the epicardial portion of the ventricle; $\# P<0.05$ - in relation to the apical part of the epicardial portion of the $L V . \wedge P<0.05$ - in relation to Group II. I - fragment of the basal region of the matrix; II - fragment of the apical region of the matrix; III - fragment of the right region of the matrix; IV fragment of the left region of the matrix. VS-ventral side of the VE; $D S$ - dorsal side of $V E$.

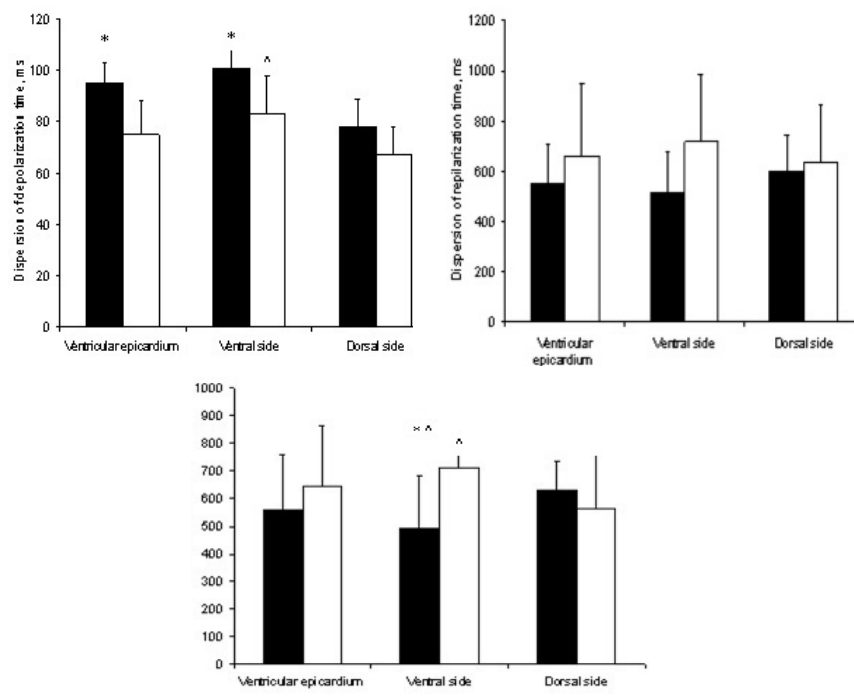

Fig. 2. Dispersion of depolarization, repolarization and ARIs times in the frog $V E$ at the body temperature of $10^{\circ} \mathrm{C}$ and $20^{\circ} \mathrm{C} . * P<0.05$ - in relation to the body temperature of $20^{\circ} \mathrm{C} . \wedge P<0.05$ - in relation to the dorsal side of the VE. $\square$ Group $I\left(10^{\circ} \mathrm{C}\right) \square$ Group $I I\left(20^{\circ} \mathrm{C}\right)$

At $20^{\circ} \mathrm{C}$, a wave of depolarization on the ventral and dorsal surfaces of the ventricle extends from the base to the apex $(P<0.05)$. The earliest AT was found in the basal part of the epicardial fragment on the ventral side, and the latest in the right part on the dorsal surface (Table 1). Dispersion of AT on the ventral and dorsal surfaces of the epicardium was $75.4 \pm 13.0 \mathrm{~ms}$, and AT on the ventral side of the ventricle was more than that on the dorsal side $(P<0.05)$ (Table 1).
Table 2.

ARIs duration different areas on the ventral and dorsal sides of the $V E$ of the frog at the body temperature of $10^{\circ} \mathrm{C}$ (Group I) and $20^{\circ} \mathrm{C}$ (Group II)

\begin{tabular}{|c|c|c|c|}
\hline \multicolumn{2}{|c|}{$\begin{array}{l}\text { Epicardial areas of } \\
\text { the ventricle }\end{array}$} & Group I & Group II \\
\hline \multicolumn{2}{|c|}{$\begin{array}{l}\text { Total duration of ARIs both } \\
\text { sides of the epicardium of } \\
\text { the ventricle of the frog }\end{array}$} & $1067.0 \pm 153.4^{*}$ & $800.8 \pm 33.5$ \\
\hline \multirow{5}{*}{ VS } & \begin{tabular}{|l} 
Duration of \\
ARIs of VS
\end{tabular} & $918.7 \pm 203.6 \# *$ & $828.4 \pm 96.3 \#$ \\
\hline & I & $926.6 \pm 150.4^{*}$ & $837.1 \pm 252.7$ \\
\hline & II & $915.5 \pm 149.4^{*}$ & $816.3 \pm 270.2$ \\
\hline & III & $939.4 \pm 141.3 *$ & $806.6 \pm 207.2^{\wedge}$ \\
\hline & IV & $919.7 \pm 152.4$ & $869.1 \pm 203.9$ \\
\hline \multirow{5}{*}{ DS } & $\begin{array}{l}\text { Duration of } \\
\text { ARIs of DS }\end{array}$ & $1215.4 \pm 325.9 *$ & $772.1 \pm 101.0$ \\
\hline & I & $1220.5 \pm 360.2 *$ & $782.4 \pm 128.6$ \\
\hline & II & $1214.1 \pm 343.4^{*}$ & $762.4 \pm 137.3$ \\
\hline & III & $1235.0 \pm 294.3^{*}$ & $764.4 \pm 200.5$ \\
\hline & IV & $1217.7 \pm 318.2 *$ & $769.5 \pm 147.2$ \\
\hline
\end{tabular}

$* P<0.05$ - in relation to Group II; $\wedge P<0.05$ - in relation to the left side epicardial fragment of VS of the ventricle; $\# P<0.05$ - in relation to the duration of ARIs on DS of the epicardial portion of LV. Ifragment of the basal region of the matrix; II - fragment of the apical region of the matrix; III - fragment of the right pane of the matrix; $I V$-fragment of the left region of the matrix; VS - ventral side of the $V E ; D S$ - dorsal side of $V E$.

It should be noted that at this temperature the duration of ARIs on the ventral surface of the VE was increased as compared with the dorsal surface $(P<0.05)$ (Table 2$)$. On the ventral side of the epicardium the largest increase in repolarization duration was observed in the left part as compared with the right part $(P<0.05)$ (Table 2). In Group II, the repolarization durations both on ventral and dorsal surfaces of the ventricle, as well as the total durations of ARIs, were less than in Group I $(P<0.05)$ (Table 2). Dispersion of ARIs time in the ventral and dorsal surfaces of the ventricle was $645.4 \pm 219.8 \mathrm{~ms}$; on the ventral side it was more than on the dorsal side $(P<0.05)$ (Fig. 2$)$. There was an increased dispersion of ARIs time on the ventral surface of the epicardium as compared with Group I $(P<0.05)$.

The repolarization sequence was directed from right to left on both surfaces of the VE (Table 1). We did not find apicobasal differences in termination time of repolarization (Table 1). Dispersion of termination time of repolarization on the ventral and dorsal surfaces of the epicardium was $662.9 \pm 285.0 \mathrm{~ms}$. There were no differences in dispersion of termination time of repolarization between the ventral and dorsal sides of the epicardium in both groups of animals (Fig. 2).

Thus when body temperature in frogs was increased to $20^{\circ} \mathrm{C}$, then the dispersion of AT and ARIs on the ventral and dorsal sides of the VE were diminished. 

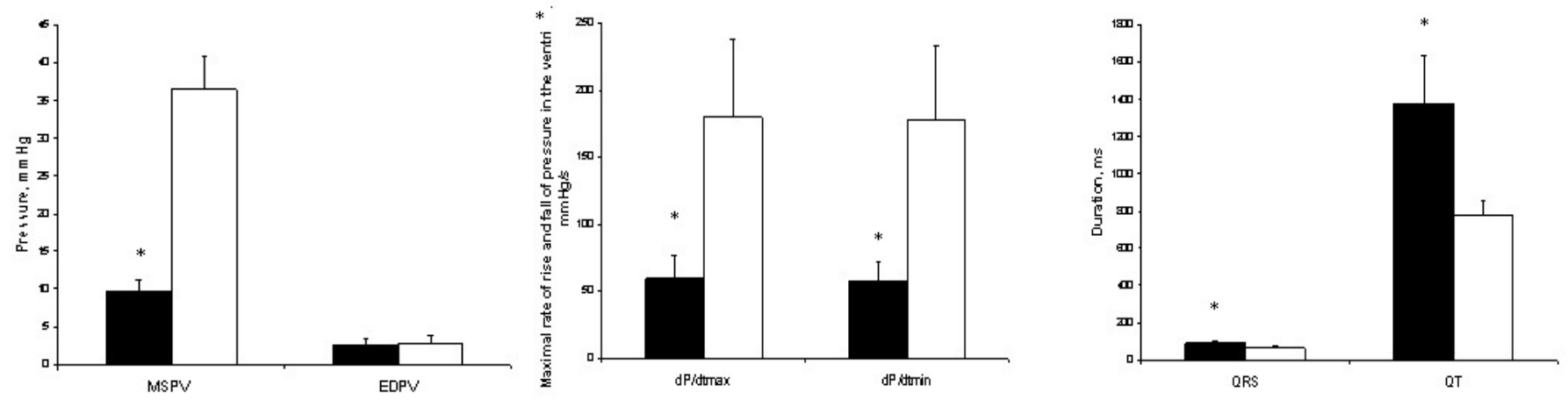

Group I $\left(10^{\circ} \mathrm{C}\right)$

Fig. 3. Parameters of pump and electrical function in the frog heart at a temperature of 10 and $20^{\circ} \mathrm{C} . \mathrm{MSPV}$ - maximal systolic pressure of the ventricle; EDPV-end-diastolic pressure of ventricle; dP/dtmax - maximal value of the MSVP derivative; dP/dtmin maximal rate of MSVP decline; $Q R S$ - duration of $Q R S$ complex in ECG; $Q T$ - duration of $Q T$ interval in ECG. ${ }^{*} P<0.05$ - in relation to body temperature of $20^{\circ} \mathrm{C}$.

\section{Dynamics of change of intraventricular pressure}

When the body temperature in frogs was increased by $10^{\circ} \mathrm{C}$, the indexes of the pump function of the ventricle were increased roughly by a factor of three: MSVP $(9.0 \pm 3.1$ vs. $36.2 \pm 6.8 \mathrm{mmHg}$; $P<0.05), \mathrm{dP} / \mathrm{dt}_{\max }(55.1 \pm 7.3 \mathrm{vs} 182.8 \pm 62.3 \mathrm{mmHg} / \mathrm{s} ; P<0.05)$ and $\mathrm{dP} / \mathrm{dt}_{\min }(49.5 \pm 6.7$ vs $175.0 \pm 60.8 \mathrm{mmHg} / \mathrm{s} ; P<0.05)$. At the same time, EDP was not changed (Fig. 3).

\section{Discussion}

The present investigation showed that in frogs, in response to the change in body temperature from $10^{\circ} \mathrm{C}$ to $20^{\circ} \mathrm{C}$, the studied indexes of the pump function of the ventricle were increased, but dispersion of depolarization time and duration of ARIs on the ventral and dorsal sides of the VE were decreased.

The rise of body temperature in studied animals causes a decrease in the duration of ARIs on the both surfaces of the VE (the tissue level of the heart organization). And at the cellular level, the duration of the action potential of ventricular cardiomyocytes is shortened in ectothermic animals with an increase in ambient temperature, ${ }^{(13-15)}$ that is, the same trend is observed.

Our study showed that in frogs, with the rise of ambient temperature there was an increase of HR and shortening of the duration of the ventricular complex of the ECG. These findings were in consistent agreement with previously obtained data. ${ }_{0}^{(8,9)}$

The regional (ventral-dorsal) changes in the repolarization process on the epicardium of frog ventricles at body temperature of $20^{\circ} \mathrm{C}$ are presented here for the first time. We assume that it is probably one of the mechanisms that ensure an adequate contractile act in response to the temperature effects.

We have found that the rise in body temperature in frogs from $10^{\circ} \mathrm{C}$ to $20^{\circ} \mathrm{C}$ causes an increase in heterogeneity of repolarization in the VE. The lack of significant changes in the excitation sequence of the VE, in dispersion of ARIs times and the termination of repolarization, possibly is due to heterogeneous change in the action potential duration of cardiomyocytes in different epicardial areas. According to the contemporary paradigm, ${ }^{(16-18)}$ the electrical and mechanical inhomogeneity of the myocardium is a modulator performing fine adjustments to the factors of the internal and external environments of the organism; that is, it performs an adaptive function.

At the same time, it is possible that there is a limiting effect of electrical heterogeneity of the myocardium to the optimal HR for a given species. ${ }^{(12)}$ The obtained results point to the existence of adaptive potential or functional reserve in the heart of the studied animals that occurs in response to the change in the ambient temperature.

\section{Limitations and perspectives of the study}

In our study, the frogs were anaesthetized by $40 \%$ ethanol. In experimental work with amphibians, authors have used different drugs for anaesthesia: methanesulfonate (MS-222), ${ }^{(19-20)}$ ether ${ }^{(5,8)}$ and urethane. ${ }^{(21)}$ Therefore, further experiments are necessary to compare effects of these drugs on the amphibian cardiovascular system. The present experiments are limited in that they provide an assessment of the processes of depolarization and repolarization only on the fragments of VE. It would be interesting to broaden these studies using ultrasound methods and an increased temperature range to examine in detail the adaptive features of cardiohemodynamics in amphibia.

\section{Competing interests}

The authors declare that they have no competing interests.

\section{Sources of Funding}

The study was supported by the Ural Branch of the Russian Academy of Sciences (Project No. 12-P-4-1003).

\section{References}

1. Wilson RS, James RS, Johnston IA. Thermal acclimation of locomotor performance in tadpoles and adults of the aquatic frog Xenopus laevic. J Comp Physiol B. 2000;170(2):117-24. 2. Johnston IA, Temple GK. Thermal plasticity of skeletal 
muscle phenotype in ectothermic vertebrates and its significance for locomotory behaviour. J Exp Biol. 2002; 205(Pt 15):2305-22.

3. Steinhausen MF, Sandblom E, Eliason EJ, Verhille C, Farrell FP. The effect of acute temperature increases on the cardiorespiratory performance of resting and swimming sockeye salmon (Oncorhynchus nerka). J Exp Biol. 2008; 211(Pt 24):3915-26. doi:10.1242/jeb.019281

4. Seebacher F, Franklin CE. Physiology of invasion: cane toads are constrained by thermal effects on physiological mechanisms that support locomotor performance. J Exp Biol. 2011;214(Pt 9):1437-44. doi: 10.1242/jeb.053124

5. Rocha PL, Branco LGS. Cardiovascular, respiratory and metabolic resposes to temperature and hypoxia of the winter frog Rana catesbeiana. Braz J Med Biol Res. 1997;30(1):125-31.

6. Sevcencu C, Ardelean C, Tarba C. Electrical and mechanical effects induced by cold temperatures in the ventricle of isolated Rana ridibunda hearts. Comp Biochem Physiol $A$. 2007;148(1):196-203. doi: 10.1016/j.cbpa.2007.04.006

7. Jensen B, Moorman A, Wang T. Structure and function of the hearts of lizards and snakes. Biol Rev Camb Philos Soc. 2014; 89(2):302-36. doi:10.1111/brv.12056

8. Chapovetsky V, Katz U. Effects of season and temperature acclimation on electrocardiogram and heart rate of toads (Bufo regularis). Comp Biochem Physiol A Mol Integr Physiol. 2003;134(1):77-83.

9. Vaǔkshnoraĭte MA, Belogolova AS, Vitiazev VA, Azarov IaE, Shmakov DN. [Cardiac electric field at the period of depolarization and repolarization of the frog heart ventricle]. Zh Evol Biokhim Fiziol. 2008;44(2):173-9. [Article in Russian].

10. Branco LG, Wood SC. Effect of temperature on central chemical control of ventilation in the alligator Alligator mississippiensis. J Exp Biol. 1993;179:261-72.

11. Azarov JE, Kibler NA, Vaykshnorayte MA, Tsvetkova AS, Kharin SN, Vityazev VA, Shmakov DN. [Effect of heart electric stimulation on repolarization of fish and amphibian ventricular myocardium]. Zh Evol Biokhim Fizol. 2013; 49(2):128-36. [Article in Russian].

12. Kibler NA, Nuzhny VP, Achmetzhynova SV, Shmakov
DN. Effects of Heart Rate on the Pump Function and Electrophysiological Characteristics of the Heart in the Frog Rana temporaria. International Journal of Biomedicine. 2017; 7(1):46-50. doi: 10.21103/Article7(1)_OA5

13. Maricondi-Massari M, Kalinin AL , Glass ML, Rantin FT. The effects of temperature on oxygen uptake, gill ventilation and ECG waveforms in the nile tilapia, Oreochromus niloticus. J Therm Biol. 1998;23(5):283-90.

14. Vornanen M, Ryökkynen A, Nurmi A. Temperaturedependent expression of sarcolemmal $\mathrm{K}(+)$ currents in rainbow trout atrial and ventricular myocytes. Am J Physiol Regul Integr Comp Physiol. 2002;282(4):R1191-9.

15. Shiels HA, Paajanen V, Vornanen M. Sarcolemmal ion currents and sarcoplasmic reticulum $\mathrm{Ca} 2+$ content in ventricular myocytes from the cold stenothermic fish, the burbot (Lota lota). J Exp Biol. 2006;209(Pt 16):3091-100.

16. Markhasin VS, Balakin AA, Katsnelson LB, Konovalov PV, Lookin ON, Protsenko Y, Solovyova O. Slow force response and auto-regulation of contractility in heterogeneous myocardium. Prog Biophys Mol Biol. 2012;110(2-3):305-18. doi:10.1016/j.pbiomolbio.2012.08.011

17. Boukens BJ, Christoffels VM. Electrophysiological patterning of the heart. Pediatr Cardiol. 2012;33(6):900-6. doi:10.1007/s00246-012-0237-4

18. Solovyova O, Katsnelson LB, Kohl P, Panfilov AV, Tsataryan AK, Tsyvian PB. Mechano-electric heterogeneity of the myocardium as a paradigm of its function. Prog Biophys Mol Biol. 2016;120(1-3):249-54. doi: 10.1016/j. pbiomolbio.2015.12.007

19. Warburton SJ, Fritsche R. Blood pressure control in a larval amphibian, Xenopus laevic. J Exp Biol. 2000;203(Pt 13):2047-52.

20. Cakir Y, Strauch SM. Tricaine (MS-222) is a safe anesthetic compound compared to benzocaine and pentobarbital to induce anesthesia in leopard frogs (Rana pipiens). Pharmacol Reports. 2005;57(4):467-74.

21. Nagai M, Iriki M. Characteristics of cardiovascular responses of the bullfrog (Rana catesbeiana) to the thermal stimulation of the spinal cord. J Comp Physiol. 1986; 156(5):611-6. 